\title{
УЧАСТНИКИ СПЕЦИАЛЬНОЙ ОЦЕНКИ УСЛОВИЙ ТРУДА. ПРАВА И ОБЯЗАННОСТИ
}

\section{ARTS OF THE SPECIAL ASSESSMENT OF WORKING CONDITIONS. RIGHTS AND OBLIGATIONS}

N. Khristoforov

Summary. There are provided evaluation of the rights and obligations of the parties involved in a special assessment of working conditions. Outline relationships such as "employer-organiztion", "employer-employee" and "employee-organiztion" are estabilished under within frame of Articles 4, 5,6 of Federal Law № 426-FL.

Keywords: special assessment of working conditions, certification of jobs, working conditions, rights and obligations of the parties, employer, employee, assessing organization

\author{
Христофоров Николай Романович \\ Аспирант, Всероссийский государственный \\ университет юстиции \\ khristoforov-n@mail.ru \\ Майоров Иван Иванович \\ Аспирант, Всероссийский государственный \\ университет юстиции \\ majorov91@yandex.ru
}

Аннотация. В статье проведен анализ прав и обязанностей сторон, участвующих в специальной оценке условий труда. Установлены такие соотношения, как «работодатель-организация», «работодатель-работник» и «работник-организация», в рамках статей 4, 5, 6 Федерального закона № 426-Ф3.

Ключевые слова: специальная оценка условий труда, аттестация рабочих мест, условия труда, права и обязанности сторон, работодатель, работник, оценивающая организация.

Работодатель имел право для проведения процедур по аттестации рабочих мест в зависимости от объема и вида выполняемых работ привлекать несколько организаций. Требовать от аттестующей организации документы, подтверждающие их компетентность. Наличие документального подтверждения аккредитации на право оказания услуг в области охраны труда и наличия организации в реестре организаций, оказывающих услуги в области охраны труда.

Функции аттестующей организации заключались в определении объема и характера информации, предоставляемые работодателем, а также объема работ и в связи с объемом работ, определение количества специалистов, привлекаемых для выполнения измерений и оценок. Аттестующая организация была обязана по требованию работодателя предоставить ему обоснование полученных результатов по аттестации рабочих мест.

Отдельно были обозначены функции аттестационной комиссии, в состав которой входили представители работодателя, представители выборного органа первичной профсоюзной организации или иного представительного органа работников, представители аттестующей организации (пункт 10 Порядка). По итогам проведенных процедур, аттестационная комиссия разрабатывала мероприятия по улучшению условий труда. 
Таблица 1. Права и обязанности сторон при проведении аттестации рабочих мест [2]

\begin{tabular}{|c|c|}
\hline № пункта & Содержание \\
\hline 5 & $\begin{array}{l}\text { о праве принятия аттестационной комиссией мотивированного решения о непроведении работ в случае } \\
\text { возникновения угрозы жизни и здоровью специалистов аттестующей организации }\end{array}$ \\
\hline \multirow{2}{*}{6} & о возложении обязанностей по проведению АРМ на работодателя \\
\hline & о праве привлечения работодателем для проведения АРМ нескольких организаций \\
\hline \multirow{4}{*}{7} & право работодателя предъявлять требования к аттестующей организации \\
\hline & обязанности работодателя при проведении АРМ \\
\hline & функции аттестующей организации \\
\hline & $\begin{array}{l}\text { об обязанности аттестующей организации по требованию работодателя предоставить и обосновать выводы } \\
\text { по результатам АРМ }\end{array}$ \\
\hline 12 & функции аттестационной комиссии \\
\hline 48 & обязанности работодателя по проведению внеплановой АРМ \\
\hline 52 & $\begin{array}{l}\text { об ответственности сторон по предоставлению информации: } \\
\text { на работодателя — предоставление информации об АРМ в государственную инспекцию труда в субъекте РФ; } \\
\text { на работодателя и аттестующую организацию за достоверность проведения измерений и оценок. }\end{array}$ \\
\hline
\end{tabular}

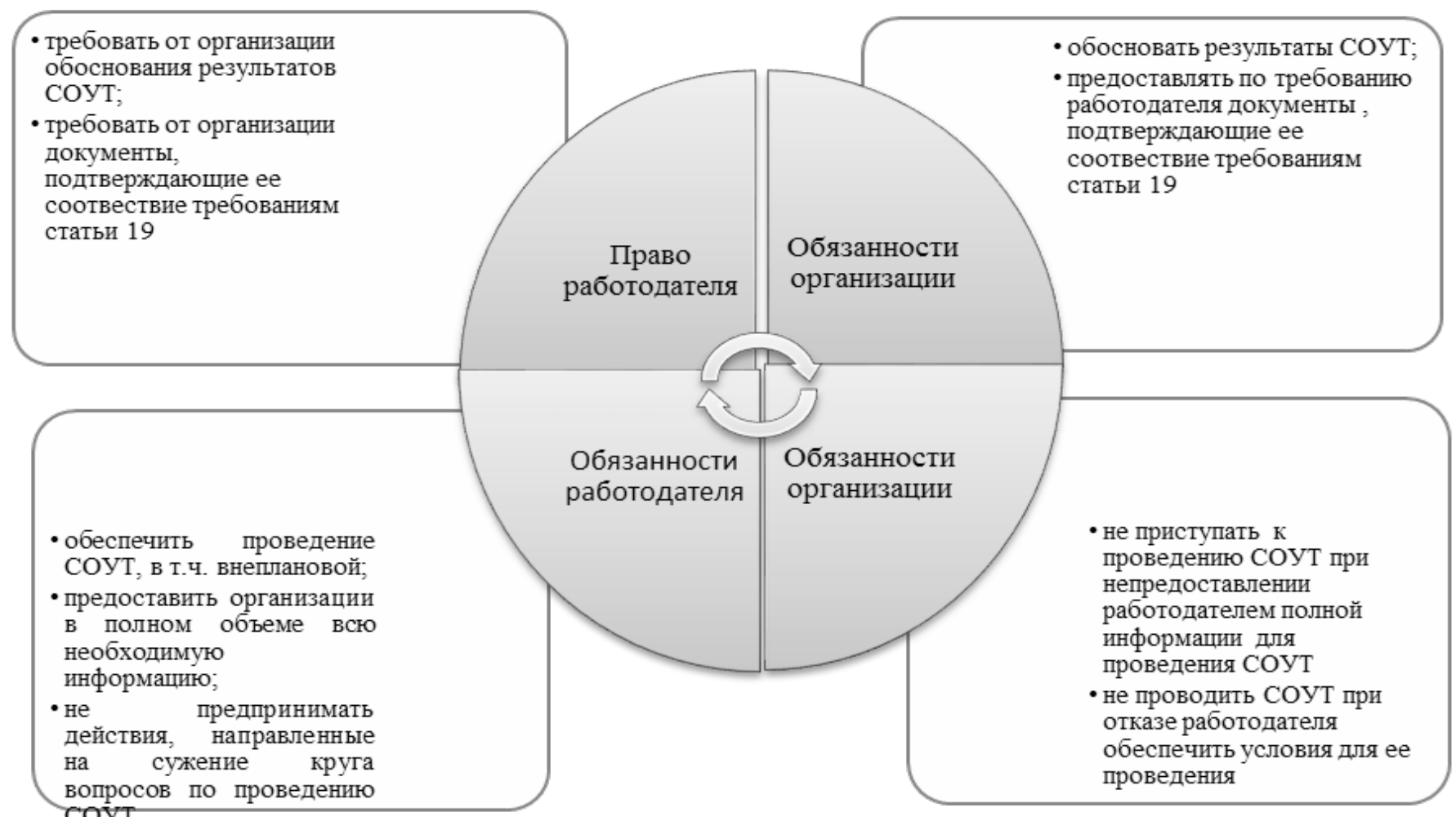

Рис. 1. Взаимоотношение «работодатель-организация»

Объектом всех мероприятий, предусмотренных Порядком проведения аттестации по условиям труда, были рабочие места и при этом субъекты, занятые на этих рабочих местах были чем-то абстрактным, не имеющим конкретных прав и обязанностей. На рабочем месте проводился определенный перечень мероприятий, а работник, занятый на данном рабочем месте и в интересах которого проводились все мероприятия, являлся как-бы просто наблюдателем. И этого молчаливого наблюда- теля работодатель знакомил с результатами аттестации под роспись (пункт 44). Кроме ознакомления с результатами, работник мог обратиться с заявлением к работодателю о проведении внеплановой аттестации рабочих мест (пункт 47). На этом все его полномочия, оговоренные в Порядке, заканчивались.

Из вышесказанного следует вывод, что в Порядке проведения аттестации по условиям труда права и обя- 
занности сторон четко не прописаны, а работник в качестве стороны, принимающей участие в процессе аттестации рабочих мест, как таковой не рассматривался [4].

Впервые в Федеральном законе № 426-Ф установлены права и обязанности сторон, участвующих в специальной оценке условий труда. Законодательно установленными сторонами, участвующими в проведении комплекса мероприятий по специальной оценке условий труда, являются работодатель, работник и организация, проводящая специальную оценку условий труда. Одним из равноправных сторон специальной оценки условий труда законодательно признан работник.

Права и обязанности сторон раскрыты статьями 4, 5 и 6 Федерального закона № 426-Ф3. Положения, изложенные в данных статьях, носят как обособленный характер, затрагивающий права и обязанности одной стороны специальной оценки, так и необособленный характер, затрагивающий две и более стороны. Исходя из положений статей 4-6 Федерального закона № 426-Ф3, рассмотрим правоотношения сторон по следующим схемам: «работодатель-организация», «работодатель-работник», «работник-организация», т.е. положения имеющие необособленный характер. Например, право работодателя требовать от организации обоснования ее результатов (пункт 1.1 статьи 4) перекликается с обязанностью организации (пункт 2.1 статьи 6). Или обязанность работодателя в письменной форме ознакомить работников с результатами специальной оценки (пункт 2.4 статьи 4) совпадает с обязанностью работника ознакомиться с ее результатами (пункт 2 статья 5).

Рассмотрим взаимоотношения «работодатель-организация» (рис. 1). Право работодателя требовать от организации обоснованных результатов, которые получены в ходе проведения специальной оценки условий труда, перекликается с обязанностью организации по обоснованию полученных результатов. При не выполнении работодателем обязанности по созданию соответствующих условий и в случае не предоставления всей необходимой информации, организация обязана работы по оценке условий труда не проводить или приостановить.

Подпункт 5 пункта 1 статьи 4 о праве работодателя предъявлять требования к организации, проводящей специальную оценку, по внесению информации об ее результатах в информационную систему, введенные Федеральным законом от 27.12.2019 N451-Ф3 [5]. В отношении данного вопроса внесены соответствующие изменения в статьи 8, 18 и 19 Федерального закона № 426. Вышеупомянутые изменения не нашли отражения в обязанностях организации, проводящей специальную оценку. В статью 18 Федерального закона № 426-Ф3 вы- шеупомянутым законом внесены изменения в части размещения информации о специальной оценке условий труда в информационную систему учета и обязанности по размещению данной информации вменены в обязанность организации, проводящей специальную оценку. Сроки проведения специальной оценки условий труда исчисляются с момента опубликования оценивающей стороной информации в систему учета (пункт 4 статьи 8). На наш взгляд, соответствующее изменение должно быть внесено в статью 6 в части обязанностей оценивающей организации. Данное положение нарушает структурированность рассматриваемого нормативного акта в отношении изложения прав и обязанностей сторон специальной оценки условий труда.

Следует отметить достаточно логично выстроенную схему в отношении «работодатель-работник». Работодатель и работник имеют право в установленном порядке обжаловать результаты специальной оценки условий труда. В отношении ознакомления с результатами проведенной специальной оценки условий труда обязанность работодателя полностью совпадает с обязанностью работника. Федеральный закон № 426-Ф3 закрепляет за работником право, как равноправной стороны процесса, вносить свои предложения по вопросам, связанным с идентификацией потенциально вредных и (или) опасных факторов производственной среды на его рабочем месте. Работник имеет право, при несогласии с результатами специальной оценки условий труда на его рабочем месте, в письменном виде изложить свои замечания и возражения. А работодатель в свою очередь, обязан рассмотреть эти замечания и возражения. Данное письменное обращение может служить основанием для проведения внеплановой специальной оценки условий труда.

Взаимоотношения «работник-организация», следует отметить, раскрыты в недостаточной мере. Необходимо статью 6 в части обязанностей организации дополнить пунктами, которые связаны со следующими правами работника:

- вносить предложения в процесс идентификации потенциально вредных и (или) опасных факторов на его рабочем месте, получать разъяснения по вопросам проведения специальной оценки условий труда (п. 1.2 ст. 5);

- представлять в письменном виде замечания и возражения относительно результатов специальной оценки на его рабочем месте (п. 1.4 ст. 5).

К обособленным правам и обязанностям сторон специальной оценки условий труда следует отнести:

- обязанности работодателя проводить мероприятия по улучшению условий труда по результатам специальной оценки условий труда; 
- обязанности организации при проведении работ применять аттестованные методики (методы);

- обязанности организации хранить коммерческую тайну, связанную с организацией, в которой проводилась специальная оценка условий труда;

- право работника присутствовать при проведении специальной оценки условий труда на его рабочем месте;

- право организации отказаться от выполнения работ случае возникновения угрозы жизни и здоровью, которая возникла в ходе проведения специальной оценки условий труда;

- право организации обжаловать предписания контролирующих и надзирающих органов.

Относительно обособленных прав и обязанностей сторон необходимо заострить внимание на подпунктах 1.2 и 2.1 статьи 4 в отношении прав и обязанностей работодателя. Подпунктом 2 пункта 1 статьи 4 проведение внеплановой специальной оценки условий труда пози- ционируется как право работодателя, а подпунктом 1 пункта 2 той же статьи проведение внеплановой является обязанностью работодателя. Проведение внеплановой специальной оценки условий труда является не правом, а обязанностью работодателя.

Необходимо предусмотреть право работника оспорить в досудебном и судебном порядке результаты проведенной специальной оценки условий труда.

В связи С принятием Федерального закона от 27.12.2019 N451-Ф3 «О внесении изменений в Федеральный закон «О специальной оценке условий труда» пункт 2 статьи 6 в части обязанностей организации дополнить следующим: «предоставлять по требованию работодателя информацию о размещении в Федеральную государственную информационную систему учета результатов проведения специальной оценки условий труда (далее - информационная система учета)».

\section{ЛИТЕРАТУРА}

1. Федеральный закон от 28.12.2013 N426-Ф3 «0 специальной оценке условий труда» Официальный интернет-портал правовой информации http://www. pravo.gov.ru, 30.12.2013, «Российская газета», N295, 30.12.2013, «Собрание законодательства РФ», 30.12.2013, N52 (часть I), ст. 6991.

2. Приказ Минздравсоцразвития РФ от 26.04.2011 № 342н «06 утверждении порядка проведения специальной оценки условий труда» (зарегистрировано в Минюсте России 9.06.2011 № 209693).

3. Саликова Н. М. Специальная оценка условий труда: проблемы соблюдения прав работников. «Бизнес, Менеджмент и Право», 2015 , № 2.

4. ирсанова Д. А. Сравнительная характеристика специальной оценки условий труда, аттестации рабочих мест и государственной экспертизы условий труда. «Современный юрист», 2016, № 3.

5. Федеральный закон от 27.12.2019 N451-Ф3 «0 внесении изменений в Федеральный закон «0 специальной оценке условий труда». Официальный интернет-портал правовой информации http://www.pravo.gov.ru, 28.12.2019, «Российская газета», N295, 30.12.2019, «Собрание законодательства РФ», 30.12.2019, N52 (часть I), ст. 7769.

(c) Христофоров Николай Романович ( khristoforov-n@mail.ru ), Майоров Иван Иванович ( majorov91@yandex.ru ). Журнал «Современная наука: актуальные проблемы теории и практики» 